\title{
Membrane Interaction of $\alpha$-Synuclein in Different Aggregation States
}

\author{
Marie Grey ${ }^{\mathrm{a}, \mathrm{d}, *}$, Sara Linse ${ }^{\mathrm{b}}$, Hanna Nilsson $^{\mathrm{c}}$, Patrik Brundin ${ }^{\mathrm{d}}$ and Emma Sparr ${ }^{\mathrm{a}}$ \\ ${ }^{a}$ Department of Physical Chemistry, Lund University, Lund, Sweden \\ ${ }^{\mathrm{b}}$ Department of Biochemistry, Lund University, Lund, Sweden \\ ${ }^{\mathrm{c}}$ Department of Biophysical Chemistry, Lund University, Lund, Sweden \\ ${ }^{\mathrm{d}}$ Neuronal Survival Unit, Wallenberg Neuroscience Center, Lund, Sweden
}

\begin{abstract}
Aggregated $\alpha$-synuclein in Lewy bodies is one of the hallmarks of Parkinson's disease (PD). Earlier observations of $\alpha$-synuclein aggregates in neurons grafted into brains of PD patients suggested cell-to-cell transfer of $\alpha$-synuclein and a prion-like mechanism. This prompted the current investigation of whether $\alpha$-synuclein passes over model phospholipid bilayers. We generated giant unilamellar vesicles (GUVs) containing a small amount of a lipid-conjugated red emitting dye (rhodamine B) and varied the membrane charge by using different molar ratios of DOPC and DOPS or cardiolipin. We then used confocal fluorescence microscopy to examine how monomer, fibril as well as on-pathway $\alpha$-synuclein species labeled with a green emitting fluorophore (Alexa488) interacted with the phospholipid bilayers of the GUV. We defined conditions that yielded reproducible aggregation kinetics under basal conditions and with none or moderate shaking. We found that on-pathway $\alpha$-synuclein species and equilibrium amyloid aggregates, but not $\alpha$-synuclein monomers, bound to lipid membranes. $\alpha$-Synuclein was particularly strongly associated with GUVs containing the anionic lipids cardiolipin or DOPS, whereas it did not associate with GUVs containing only zwitterionic DOPC. We found that $\alpha$-synuclein progressively aggregated at the surface of the GUVs, typically in distinct domains rather than uniformly covering the membrane, and that both lipid and protein were incorporated in the aggregates. Importantly, we never observed transport of $\alpha$-synuclein over the GUV bilayer. This suggests that $\alpha$-synuclein transport over membranes requires additional molecular players and that it might rely on active transport.
\end{abstract}

Keywords: $\alpha$-synuclein, Parkinson's disease, aggregation, membrane, fibril, oligomer, lipid bilayers, amyloid

\section{INTRODUCTION}

$\alpha$-Synuclein is a small (140-amino acid), negatively charged and possibly natively unfolded protein found in the brain. In Parkinson's disease (PD), $\alpha$-synuclein aggregates, together with lipids and mitochondria, into Lewy bodies and Lewy neurites, which are the neuropathological hallmarks of the disease $[1,2]$. Point mutations in the gene encoding $\alpha$-synuclein lead to autosomal dominant PD [3-5]. Furthermore, overexpression of $\alpha$-synuclein due to gene duplication

*Correspondence to: Marie Grey, Physical Chemistry, Center for Chemistry and Chemical Engineering, Lund University, P.O. Box 124, SE-221 00, Lund, Sweden. E-mail: marie.grey@fkem1.lu.se. or triplication leads to neurological disease featuring parkinsonian signs and symptoms [6, 7].

Purified, recombinant $\alpha$-synuclein, can readily be isolated in monomeric state by size exclusion chromatography. In the healthy human brain, however, a recent report suggests that the native protein primarily exists as a low-n oligomer, possibly a tetramer [8]. The mechanism whereby $\alpha$-synuclein mediates neurotoxicity is not clear and it is debated whether the $\alpha$-synuclein aggregates per se are toxic or represent a way by which cells' disarm more toxic intermediate $\alpha$-synuclein species $[9,10]$. As a possible pathogenetic mechanism, it has been suggested that oligomeric $\alpha$-synuclein causes membrane permeabilisation or channel formation in the outer cell 
membrane [11-13]. Mitochondrial dysfunction has also been highlighted as an important contributor to PD pathogenesis. $\alpha$-Synuclein preferentially binds mitochondria [14] and in the substantia nigra of PD patients the amount of $\alpha$-synuclein associated to mitochondria is increased [15]. Mitochondria are rich in the negatively charged lipid cardiolipin and $\alpha$-synuclein associates with this and other anionic lipids [16-18].

Biological membranes contain a high fraction of neutral phospholipids like the zwitterionic 1,2-dioleoyl-sn-glycero-3-phosphocholine (DOPC). Depending on the subcellular location of the membrane, the neutral phospholipids occur in combination with a large number of other lipids. The lipid composition of the two leaflets of a biological membrane typically varies and this asymmetry in composition may change upon rupture or cellular events [19]. Model membranes in the form of vesicles will have the same composition in the inner and outer leaflet, and properties like net charge, domain (raft) formation and membrane fluidity can easily be fine-tuned by using a defined lipid mixture during production.

Several recent reports describe that healthy neurons grafted into the brains of PD patients can develop Lewy bodies $[20,21]$. While the mechanisms underpinning the formation of Lewy bodies are not fully understood yet [22], it has been suggested that misfolded $\alpha$-synuclein is transferred from diseased to healthy cells and triggers $\alpha$-synuclein aggregation in a prionlike fashion [23, 24]. Recent studies in cell cultures and experimental animals confirm that $\alpha$-synuclein can transfer between neurons and, once inside the new cell, can act as a seed for protein aggregation [25-27].

In the present study, we use confocal fluorescence microscopy to investigate whether different molecular forms of $\alpha$-synuclein associate with phospholipid model membranes, and if any of the $\alpha$-synuclein species can traverse these membranes. Specifically we compared on-pathway samples with monomeric $\alpha$-synuclein and fibrillar samples at equilibrium, taking advantage of our highly reproducible $\alpha$-synuclein aggregation kinetics under basal conditions and with none or moderate shaking. On-pathway oligomers are difficult to isolate and enrich due to their dynamic nature with conversion backward to smaller species and forward to larger aggregates. Using our reproducible protocol, we could compare the outcome when adding the different species of $\alpha$-synuclein to giant unilamellar vesicles (GUVs). We prepared membranes in the form of GUVs composed of DOPC (charge 0) mixed with either DOPS (charge -1, a major lipid component of the inner leaflet of the plasma membrane in human cells) or cardiolipin (charge -2, found in mitochondrial membranes). We never observed $\alpha$-synuclein traversing the GUV bilayer. Instead $\alpha$-synuclein progressively aggregated in distinct domains at the surface of the GUVs containing cardiolipin or DOPS, whereas it did not associate with GUVs containing only DOPC.

\section{MATERIALS AND METHODS}

\section{Materials}

We obtained 1', 3'-bis(1,2-dioleoyl-sn-glycero-3phospho)-sn-glycerol sodium salt (cardiolipin, CL), 1,2-dioleoyl-sn-glycero-3-phospho-L-serine sodium salt (DOPS) and 1,2-dioleoyl-sn-glycero-3-phosphocholine (DOPC) from Avanti Polar Lipids (Alabaster $\mathrm{AL})$ together with 1,2-dimyristoyl-sn-glycero2-phosphoethanolamine- $\mathrm{N}$-(lissamine rhodamine B sulfonyl) ammonium salt. Buffer chemicals MES2-(NMorpholino)ethanesulfonic acid, sodium phosphate, $\mathrm{NaCl}, \mathrm{CaCl}_{2}$, and ThT were of analytical grade.

\section{$\alpha$-Synuclein}

We expressed human $\alpha$-synuclein in Escherichia coli from the aS-pT7-7 plasmid (kindly provided by $\mathrm{H}$. Lashuel) and purified using heat treatment, ion exchange and gel filtration chromatography as follows. The plasmid was transformed into $E$. coli BL21 Star PLysS DE3 $\left(\mathrm{Ca}^{2+}\right.$ competent cells) by heat shock and grown on LB/agar plates with $50 \mathrm{mg}$ ampicillin and $30 \mathrm{mg} / \mathrm{l}$ chloramphenicol. Single colonies were used to inoculate $50 \mathrm{ml}$ overnight cultures (LB with $50 \mathrm{mg}$ ampicillin per 1) and $5 \mathrm{ml}$ was then transferred to each $500 \mathrm{ml}$ day culture of the same medium. IPTG was added when OD600 reached 0.6 and the cells were harvested 4 hours later and the cell pellet frozen. Cells were disrupted by sonication in ice-cold $10 \mathrm{mM}$ Tris/HCl, 1 mM EDTA, pH 7.5 (buffer A), followed by centrifugation at $15000 \mathrm{~g}$ for $10 \mathrm{~min}$. The supernatant was loaded onto a DEAE cellulose column equilibrated in buffer A. The protein was eluted using a linear salt gradient from $0-0.5 \mathrm{M} \mathrm{NaCl}$, and examined using agarose gel electrophoresis. Fractions containing $\alpha$ synuclein were pooled, lyophilized and subjected to gel filtration on a G50 column $(3.4 \times 200 \mathrm{~cm})$. Fractions containing $\alpha$-synuclein were pooled, $\mathrm{pH}$ adjusted to 7.5 , loaded onto a DEAE sephacel column in $10 \mathrm{mM}$ Tris/ $\mathrm{HCl} \mathrm{pH} 7.5$ and eluted using a linear $\mathrm{NaCl}$ gradient from $0-0.5 \mathrm{M}$. Fractions containing $\alpha$-synuclein were pooled. The pool was found to contain $0.1-0.3 \%$ 
of a contaminating protein from $E$. coli, and was therefore heated to $90^{\circ} \mathrm{C}$ followed by rapid cooling and centrifugation. The resulting supernatant contained pure $\alpha$-synuclein and was stored as frozen aliquots $\left(-20^{\circ} \mathrm{C}\right)$. In the following batches the boiling step was performed in the beginning of the protocol instead.

\section{Vesicle preparation}

We prepared giant unilamellar vesicles (GUVs) by electroformation $[28,29]$ in a custom-built chamber with Pt electrodes [30]. Lipids dissolved in chloroform $/ \mathrm{MeOH} 2: 1(\mathrm{v} / \mathrm{v})(0.2 \mathrm{mg} / \mathrm{ml})$ were deposited on the Pt electrodes using a Hamilton syringe and the solvent evaporated in a vacuum chamber for at least $2 \mathrm{~h}$. After adding $200 \mu \mathrm{l}$ of a suitable buffer $(10 \mathrm{mM}$ MES pH 5.5 or $10 \mathrm{mM} \mathrm{NaP} \mathrm{pH} \mathrm{7.5)} \mathrm{into} \mathrm{the} \mathrm{chamber}$ a voltage of $2 \mathrm{~V}$ peak-to-peak and $50 \mathrm{~Hz}$ was applied for $30 \mathrm{~min}$ where after the voltage was increased to $6 \mathrm{~V}$ peak-to-peak for $2 \mathrm{~h}$. GUVs were prepared of DOPC or mixtures of DOPC and CL or DOPC and DOPS, and the fluorescent lipid analogue was added at a concentration of $0.01 \mathrm{~mol} \%$ of the total amount of lipids. Before addition of protein sample the chamber buffer volume was halved.

\section{$\alpha$-Synuclein aggregation}

The monomer was purified by size exclusion chromatography (SEC) on a Superdex 75 column (GE Healthcare) in experimental buffer (10 mM MES pH 5.5 or $10 \mathrm{mM} \mathrm{NaP} \mathrm{pH} 7.5$ ) just prior to setting up the kinetics measurements. The $\alpha$-synuclein concentration was determined using an extinction coefficient of $0.4 \mathrm{mg}^{-1} \mathrm{~cm}^{-1}$ at $280 \mathrm{~nm}$, and the samples were diluted to $0.4 \mathrm{mg} / \mathrm{ml}$ in either MES or NaP buffer ( $\mathrm{pH}$ adjusted to $5.0,5.5,6.0,6.5,7.0$ or 7.5 using phosphoric acid), and supplemented with $20 \mu \mathrm{M}$ Thioflavin $\mathrm{T}$ in order to follow the fibrillation process. The samples were prepared on ice and then aliquoted in a 96-well plate (non-treated black polystyrene, full volume plates, 3631 CoStar) and finally sealed with a plastic film to avoid evaporation. The plate was incubated at $37^{\circ} \mathrm{C}$ for up to 96 hours in a FluoStar Omega plate reader and kept at quiescent conditions or shaken at $300 \mathrm{rpm}$ between reads as desired.

The fibrils were prepared at $\mathrm{pH} 5.5$ at moderate shaking $(300 \mathrm{rpm})$ or at $\mathrm{pH} 7.5$ at vigorous shaking (2200 rpm). The fibrils were then sonicated to obtain a homogenous solution of dispersed fibrillar $\alpha$-synuclein aggregates, which were added to the GUV solution.

\section{Confocal fluorescence microscopy}

We captured images with a Zeiss LSM 510 Meta inverted microscope. The green and red fluorescence signals were acquired using double excitation $(488 \mathrm{~nm}$ from a Argon/2 laser and $561 \mathrm{~nm}$ from a DPSS 56110 laser) and detection (BP 505-550 and LP 575). The GUVs were inspected by microscopy before the addition of the protein. Protein samples were added to a final concentration of $13 \mu \mathrm{M}$ (monomer) or $6 \mu \mathrm{M}$ (fibrils equivalent monomer concentration) at least $90 \mathrm{~min}$ prior to analysis (unless otherwise stated) to allow also relatively slow interactions to take place.

\section{RESULTS}

\section{Kinetics of $\alpha$-synuclein fibril formation}

We followed the kinetics of $\alpha$-synuclein amyloid formation by ThT fluorescence. When the ThT dye binds to amyloid fibrils and oligomers, it enters a less polar environment, which gives rise to an increase in fluorescence signal at $482 \mathrm{~nm}$ when excited at $442 \mathrm{~nm}$. From the ThT data, we obtained a characteristic lag-time for the amyloid formation process and an elongation rate as determined from the slope of the increasing fluorescence signal [31, 32]. The method is operational in that it does not provide direct molecular information, and the specificity and mechanism of ThT binding in the pathway of amyloid formation is still debated. However, it is very powerful in that it is a straightforward way to monitor the process of amyloid formation. Further, if care is taken to start from homogeneous monomeric sample in degassed buffers, it enables studies where the aggregation kinetics is well controlled and highly reproducible, as previously reported [31, 33] (Cohen submitted 2011). To allow for statistical analyses we followed the $\alpha$-synuclein amyloid formation for multiple replicates in wells of a 96 well plate using a FluoStar Omega plate reader. The lag-time was defined as the time when the fluorescence reached $10 \%$ of its end value. We performed the experiment in a pure buffer system with no unwanted co-solvent such as DMSO or HFIP present.

Amyloid formation for $\alpha$-synuclein using mild shaking in two buffer systems $(10 \mathrm{mM} \mathrm{NaP}$ and $10 \mathrm{mM}$ MES buffer) and a protein concentration of $0.4 \mathrm{mg} / \mathrm{ml}$ $(28 \mu \mathrm{M})$ was followed at $\mathrm{pH}$ 5.0-7.5 pH (Fig. 1). We performed at least 8 replicates for each experiment, and found the aggregation kinetics to be highly reproducible (Fig. 1). Clearly $\mathrm{pH}$ has a very strong influence on the aggregation kinetics (Fig. 1a-c), with 

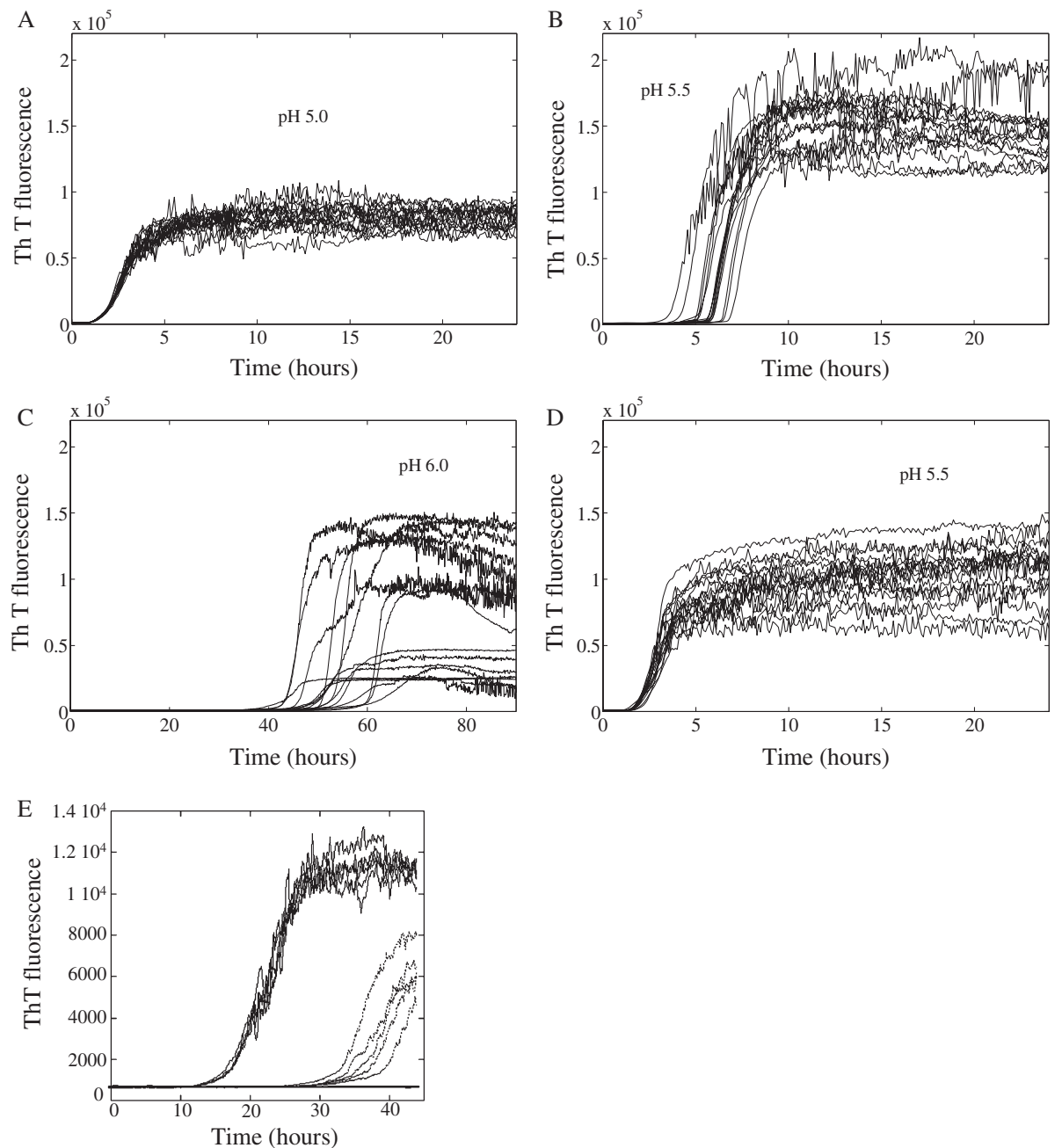

Fig. 1. Aggregation of $0.4 \mathrm{mg} / \mathrm{ml} \alpha$-synuclein in $10 \mathrm{mM} \mathrm{NaP}$ or MES buffer at different $\mathrm{pH}$. a) NaP buffer at $\mathrm{pH} 5.0$, b) NaP buffer at $\mathrm{pH} 5.5$ c) $\mathrm{NaP}$ buffer at $\mathrm{pH} 6.0, \mathrm{~d}$ ) MES buffer at $\mathrm{pH} 5.5$ and e) MES buffer at $\mathrm{pH} 5.5$ (solid line, left) and $\mathrm{pH} 6.0$ (dotted line, right). All data acquired at $37^{\circ} \mathrm{C}$ and, $300 \mathrm{rpm}$ except panel e) where quiescent conditions were used.

$\alpha$-synuclein aggregating faster at lower $\mathrm{pH}$. At $\mathrm{pH} 7.0$ and 7.5 , the aggregation did not start during the 90 hours of the experiments. Thus in our model system at physiological $\mathrm{pH}$, we do not observe aggregation, in agreement with previous reports [34]. Reproducible aggregation kinetics for $\alpha$-synuclein at $\mathrm{pH} 7.5$ was, however, observed under condition of vigorous shaking $(1000 \mathrm{rpm})$ with a lag-time of less than $30 \mathrm{~min}$ for protein concentration of $0.4 \mathrm{mg} / \mathrm{ml}$ at $37^{\circ} \mathrm{C}(10 \mathrm{mM}$ Tris- $\mathrm{HCl}$ buffer $\mathrm{pH} 7.5$ with $0.2 \% \mathrm{NaN}_{3}$ ). Increasing the ionic strength in the buffer by adding $\mathrm{NaCl}$ or $\mathrm{CaCl}_{2}$ leads to a slower aggregation process both at $\mathrm{pH} 5.5$ and $\mathrm{pH}$ 7.5. This is in contrast to what would be expected from simple screening of long-range electrostatic repulsion, suggesting a more complex structural origin.
In the subsequent studies of the interaction between aggregating $\alpha$-synuclein and lipid membranes, we used $10 \mathrm{mM}$ MES buffer, pH 5.5 (Fig. 1d). The lag time measured in $10 \mathrm{mM}$ MES buffer was shorter compared to in $10 \mathrm{mM} \mathrm{NaP}$ buffer $(2.2 \pm 0.2 \mathrm{~h}$ vs. $5.8 \pm 0.8 \mathrm{~h})$ probably related to the higher ionic strength in the $\mathrm{NaP}$ buffer.

Another important conclusion for the subsequent studies is that the aggregation process was accelerated by seeding with $10 \%$ sonicated $\alpha$-synuclein fibrils in $10 \mathrm{mM}$ MES pH 5.5 at $37^{\circ} \mathrm{C}$ and $300 \mathrm{rpm}$. Finally, we investigated the aggregation kinetics at quiescent conditions, and found that the data are highly reproducible also in complete absence of shaking, when the process was studied at pH 5.5 and 6.0 (Fig. 1e). 
$\alpha$-Synuclein association with lipid model membranes with different lipid composition

We studied the interaction between the aggregating amyloid protein $\alpha$-synuclein and model lipid membranes using confocal laser scanning microscopy and model systems of giant unilamellar lipid vesicles (GUVs) to which $\alpha$-synuclein was added. This approach allows investigation of whether the aggregating protein associates with the membrane, and whether the interaction affects the membrane properties. Using different fluorescent probes, these techniques allow simultaneous monitoring of the formation of protein aggregates, their localization, the morphology of the membrane, and the intactness of the membrane barrier. The protein-lipid interactions were investigated for monomeric, fibrillar and on-pathway aggregates of $\alpha$-synuclein at different $\mathrm{pH}$ and different membrane charge density.

We used $\alpha$-synuclein that either was unlabeled or labeled with Alexa488. In a separate kinetic study, Alexa-tagged $\alpha$-synuclein aggregation was confirmed with a lag time comparable to that of the unlabeled protein (data not shown). The lipid bilayer in the form of GUVs was visualized by including the fluorescent lipid analogue, rhodamine-PE in the lipid mixture $(0.01 \mathrm{~mol} \%)$. The model lipid membranes were composed of different lipid classes. We chose to have the most common type of phospholipids in human cell membranes, phosphatidyl choline (PC), as the primary lipid component of the GUVs. In the model membrane systems investigated, PC was mixed with anionic lipids, either phosphatidyl serine (PS), which is a major lipid component of the inner leaflet of the plasma membrane in human cell, or cardiolipin (CL) that is abundant in mitochondrial membranes.

We captured confocal microscopy images of model systems composed of fibrils of Alexa488 $\alpha$-synuclein (green) and GUVs (red) with different lipid compositions and at different $\mathrm{pH}$ after incubation in the imaging cell for at least $90 \mathrm{~min}$ (Fig. 2). The aggregated protein clearly associated with the model membranes composed DOPC and $29 \mathrm{~mol} \%$ DOPS at $\mathrm{pH} 5.5$ (Fig. $2 \mathrm{a}-\mathrm{c}$ ). The protein aggregates were present in the membrane in patches rather than uniformly covering the complete membrane surface (Fig. 2c), and we observed thickening of the membrane in these domains (Fig. 2a). Non-adsorbed $\alpha$-synuclein aggregates were present in the solution (Fig. 2b, arrows), although we never observed such aggregates inside the vesicles. Another important observation was that lipids and $\alpha$-synuclein aggregates were co-localized in the membrane (Fig. 2b). We made similar observations of membrane adsorption, membrane thickening and lipid-protein co-localization when the divalent anionic lipid CL was replaced by the monovalent anionic lipid DOPS (Fig. 2d). At pH 7.5, on the other hand, we saw no adsorption to membrane or membrane thickening after the addition of sonicated fibrillar $\alpha$-synuclein aggregates for any of the studied lipid compositions (Fig. 2e).

We could not detect protein association to the membrane composed of purely zwitterionic DOPC at any $\mathrm{pH}$ investigated (Fig. 2f, Table 1). This implies that the presence of anionic lipids is crucial to the protein-lipid interaction. Interestingly, there is protein adsorption to the bilayers with $3 \% \mathrm{CL}$, while no adsorption is detected to DOPC/DOPS bilayers with even higher charge (10\% DOPS, Table 1). We did not further quantify the amount of adsorbed protein to lipid membranes with different lipid composition, as the GUV - fibril samples were heterogeneous in concentration (no convection applied).

\section{$\alpha$-Synuclein association with lipid model membranes - effects of aggregation state}

Amyloid formation goes from the monomeric protein to large fibrillar aggregates that contain thousands of proteins. The intermediate oligomeric species have received much attention as they are considered the most toxic species and potentially also interact most with lipid membranes [9, 35-37]. At a certain position along the aggregation pathway, the sample is likely a polydisperse mixture of oligomeric species of different size, and the sample composition with respect to aggregate size vary with time. In the present study we defined the intermediates with respect to their position along aggregation kinetic trace, and we distinguished between monomeric protein and on-pathway and fibrillar protein aggregates. This approach was possible as our system provides well-defined and reproducible aggregation kinetics (Fig. 1).

We used confocal microscopy to monitor monomeric protein, on-pathway aggregates and sonicated fibrils incubated with GUV's composed of DOPC and $3 \mathrm{~mol} \% \mathrm{CL}$ (Fig. 3). The on-pathway aggregates used here were collected after 2 hours of shaking, which corresponds to ca. $89 \%$ of the lag-time (compare Fig. 1). When monomeric $\alpha$-synuclein is added to the GUVs, we see a homogenous green solution that surrounds the lipid vesicles (Fig. 3a). It is clear from the confocal images that no monomeric protein is detected inside the vesicles, implying that it 

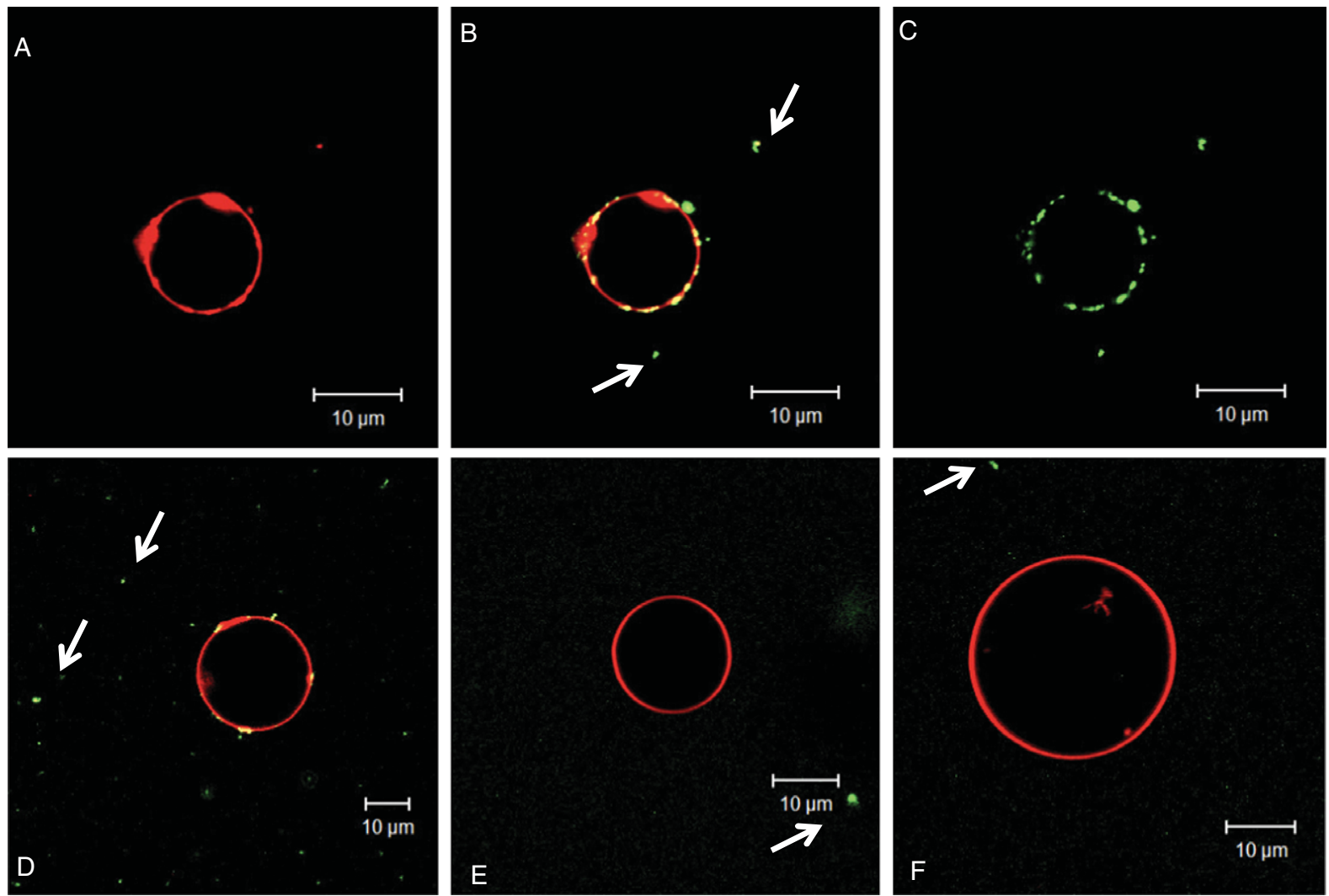

Fig. 2. Confocal microscopy images of sonicated $\alpha$-synuclein fibrils labeled with Alexa488 (green) added to GUVs of different lipid composition and $0.01 \mathrm{~mol} \%$ RH-PE (red) and $\mathrm{pH}$. Arrows denote non-adsobed $\alpha$-synuclein aggregates. a-c) GUVs composed of DOPC with $12 \% \mathrm{CL}$ in $10 \mathrm{mM}$ MES pH 5.5 (red, overlay and green), d) GUVs composed of DOPC with 29\% PS in $10 \mathrm{mM}$ MES pH 5.5 (overlay), e) GUVs compoed of DOPC with 29\% PS in $10 \mathrm{mM} \mathrm{NaP} \mathrm{pH} 7.5$ (overlay) and f) GUVs composed of pure DOPC in $10 \mathrm{mM}$ MES pH 5.5 (overlay). Non-adsorbed $\alpha$-synuclein aggregates are also present in the solution and indicated with arrows.

Table 1

Summary of when interaction between $\alpha$-synuclein and lipid is present or not. "yes" indicates that protein adsorption is seen while "no" indicates no protein adsorption to the lipid model membranes

\begin{tabular}{llc}
\hline Lipid composition & $\mathrm{pH} \mathrm{5.5}$ & $\mathrm{pH} \mathrm{7.5}$ \\
\hline DOPC & No & No \\
DOPC $+3 \% \mathrm{CL}$ & Yes & No \\
DOPC $+6 \%$ CL & Yes & - \\
DOPC $+12 \%$ CL & Yes & - \\
DOPC $+10 \%$ DOPS & No & No \\
DOPC $+29 \%$ DOPS & Yes & No \\
\hline
\end{tabular}

cannot pass the bilayer membrane. Furthermore, we observed no protein adsorption to the membrane or lipid-protein co-localization during the first $90 \mathrm{~min}$. However, after 2 hours of incubation we observed membrane association of $\alpha$-synuclein. Importantly, the distribution of the $\alpha$-synuclein was heterogeneous in the GUV membrane and found in domains that contained lipids and protein (Fig. 3b). The proteincontaining domains are typically larger with respect to membrane area compared to those formed after incubation with sonicated fibrils, although membrane thickening cannot be detected within the resolution of the technique. Not all $\alpha$-synuclein remains monomeric after the incubation, as fibrillation occurs also when no shaking is applied to the system. The adsorbed $\alpha$ synuclein is therefore likely a mixture of on-pathway oligomeric species, and there may also be a very small amount of mature fibrils. The results obtained after incubation with monomeric $\alpha$-synuclein were similar to those obtained after incubation of the on-pathway ( $2 \mathrm{~h}, 89 \%$ of lag time) aggregates (Fig. 3c), while the addition of sonicated fibrils typically give smaller and thicker domains, in which isolated particles of proteins often are detected (Fig. 3d). We found that GUVs made of DOPC/DOPS ( $\mathrm{pH} 5.5$ ) adsorbed fibrillar $\alpha$ synuclein and on-pathway aggregates. We did not, however, detect protein adsorption for any aggregation state or lipid composition at $\mathrm{pH}$ 7.5, and not for GUVs composed of purely DOPC at any $\mathrm{pH}$ investigated. 

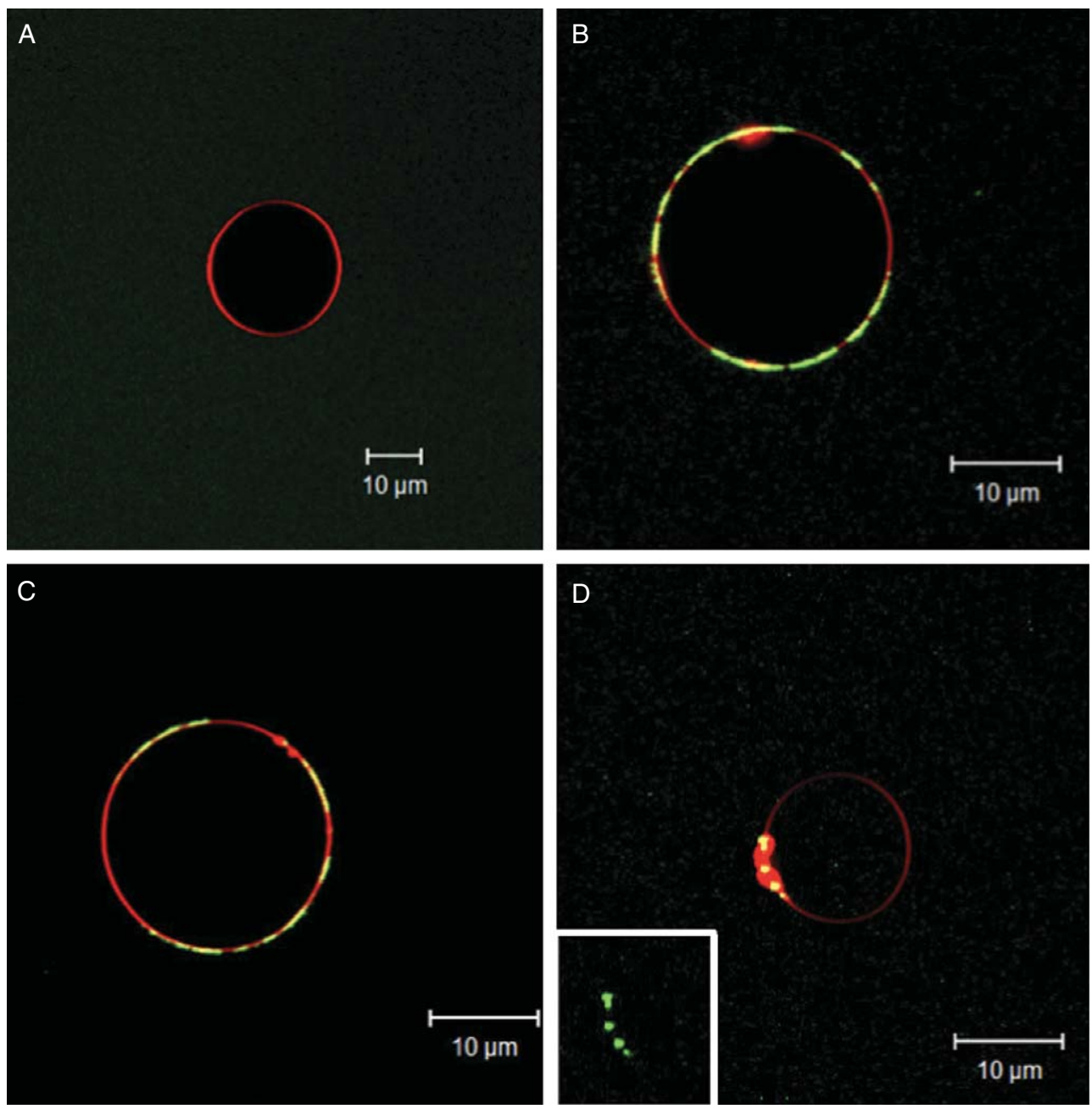

Fig. 3. Confocal microscopy images showing addition of Alexa488 labeled $\alpha$-synuclein (green) in different stages of aggregation to GUVs composed of DOPC with $3 \% \mathrm{CL}$ and $0.01 \mathrm{~mol} \%$ RH-PE (red). a) $\alpha$-synuclein monomer directly after addition, b) $\alpha$-synuclein monomer after $2 \mathrm{~h}$ of incubation with GUVs at room temperature $\left.\left(22^{\circ} \mathrm{C}\right), \mathrm{c}\right) \alpha$-synuclein on-pathway (allowed to aggregate for $2 \mathrm{~h}$ at $37^{\circ} \mathrm{C}$ ) after $2 \mathrm{~h}$ of incubation with GUVs at room temperature and d) $\alpha$-synuclein sonicated fibrils after $2 \mathrm{~h}$ of incubation with GUVs at room temperature.

Interestingly, the protein associated to the membrane in segregated domains rather than forming a uniform layer in the membrane. Furthermore, the domains were generally smaller and the membrane was thicker after adding fibrils compared to the domains formed after the addition of on-pathway oligomers (and monomers?). We analyzed the vesicle perimeter covered by labeled $\alpha$-synuclein for DOPC GUVs with either 3\% CL or $29 \%$ PS. The fraction of the GUV perimeter that was covered by labeled $\alpha$-synuclein differed between the two aggregation states. Typically after $2 \mathrm{~h}$ of incubation $\alpha$-synuclein monomer covered around 50-60\% of the GUV perimeter, on-pathway aggregates around $30-40 \%$ and sonicated fibrils $10-15 \%$. In our analysis we only monitored the size of the domains and not their thickness. As domains in samples incubated with monomer for $2 \mathrm{~h}$ typically were thinner and domains in samples subjected to sonicated fibrils thicker, the total amount of adsorbed $\alpha$-synuclein might have been the same, but the distribution different. In other words, the analysis illustrates that the domain formation depends on the $\alpha$-synuclein aggregation state, still the adsorbed amount was not quantified.

\section{Following aggregation growth in the presence of lipid model membranes}

The protein aggregation process is expected to continue in the measuring cell also after the addition of the aggregating protein to the lipid vesicles. We therefore 

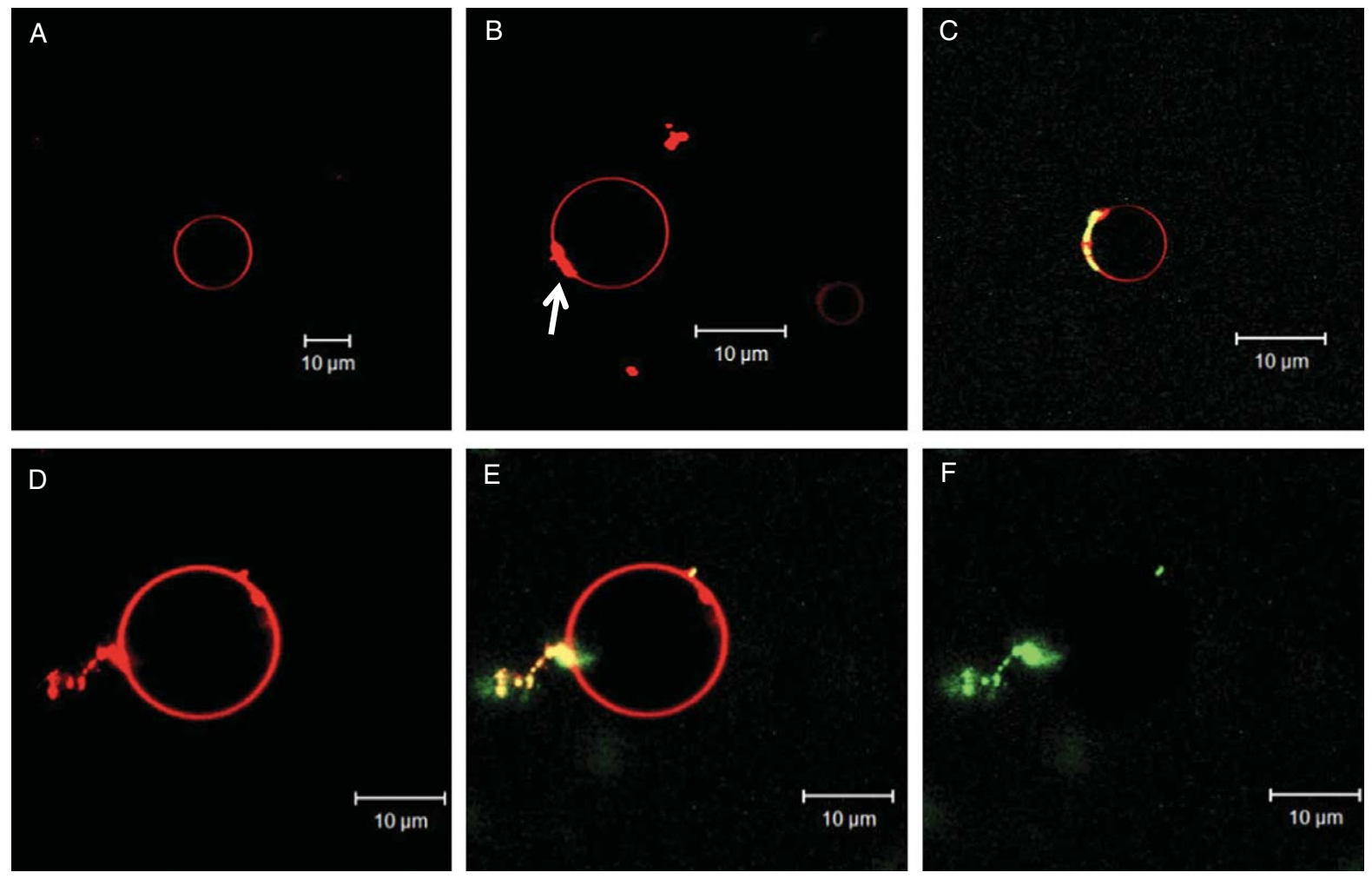

Fig. 4. Confocal microscopy images of aggregation growth followed in DOPC GUVs with $29 \%$ PS and 0.01 mol\% RH-PE (red). a) example of vesicle before addition of protein, b) after addition of unlabeled $\alpha$-synuclein and incubation for $2 \mathrm{~h}$ at room temperature, $\mathrm{c}$ ) after addition of labeled $\alpha$-synuclein monomer (green) and incubation for another $2 \mathrm{~h}$ at room temperature and $\mathrm{d}-\mathrm{f}$ ) incubation for another $10 \mathrm{~h}$ (red, overlay and green). The thickening presumably caused by $\alpha$-synuclein- lipid interaction is marked by an arrow.

performed a set of experiments to study the process of seeded protein aggregation in the presence of lipid membranes composed of DOPC and 29 mol\% DOPS (Fig. 4). Once again, we visualized the lipid membrane in the GUVs by adding a fluorescent lipid analogue (0.01 mol\% Rh-PE). First, we added non-labeled sonicated $\alpha$-synuclein fibrils to the solution containing the GUV's. After 2 hours of incubation, we observed that some domains in the lipid membrane were thicker compared to the rest of the bilayer (Fig. 4b, arrow). The structure resembled the thicker domains observed after the addition of labeled $\alpha$-synuclein (compare e.g., Figs. 2a and 3d), and the domains presumably contain also aggregated $\alpha$-synuclein. We then added Alexa488labeled $\alpha$-synuclein monomers to the same sample. After 2 hours of incubation, the thicker patches in the membrane now also contain labeled $\alpha$-synuclein (Fig. 4c), implying that the aggregates continue to grow and include the labeled $\alpha$-synuclein monomers. After longer incubation, the aggregates have grown larger (Fig. 4 d-f). Interestingly, the aggregates associated to the membrane contained both lipids and protein. We observed similar aggregates when using model membranes composed of DOPC and $3 \mathrm{~mol} \% \mathrm{CL}$.

\section{DISCUSSION}

Our results indicate that 1) $\alpha$-synuclein aggregates in a highly predictable and reproducible manner with no or moderate shaking, 2) aggregated $\alpha$-synuclein (fibrillar or on-pathway species) associates with phospholipid membranes (DOPC:DOPS or DOPC:cardiolipin), 3) $\alpha$-synuclein co-aggregates with membrane lipids and 4) $\alpha$-synuclein does not traverse model membranes.

We found that $\alpha$-synuclein fibrillates in a reproducible manner even at quiescent conditions using mildly acidic, physiologically relevant $\mathrm{pH}$ conditions. Provided that the monomer is isolated by gel filtration just prior to starting the kinetic experiment in degased buffer, we obtain reproducible kinetic data both at quiescent conditions and slow orbital shaking (100-300 rpm). This gave us access to on-pathway 
oligomeric species of $\alpha$-synuclein, which we used in our studies of membrane interaction of $\alpha$-synuclein. We found that $\alpha$-synuclein associated with model membranes containing anionic lipids, however, only for on-pathway and aggregated forms. When adsorption had occurred, that site acted as seed where aggregates that contained both protein as well as lipid grew. Importantly, we never found evidence that $\alpha$-synuclein had transversed the membrane, indicating that the passage of $\alpha$-synuclein across membrane requires an active mechanism that is not operative in our model system.

\section{Reproducible aggregation of $\alpha$-synuclein}

We achieved reproducible aggregation kinetics of human $\alpha$-synuclein under mildly acidic conditions. The 140 amino acid sequence of $\alpha$-synuclein contains 25 acidic and 16 basic groups with markedly asymmetric distribution, giving a net charge of -9 at neutral or slightly basic $\mathrm{pH}$. Negative charges dominate in the $\mathrm{C}$-terminal region and whereas the central region has few charges, the $\mathrm{N}$-terminus is positively charged. A slight reduction in $\mathrm{pH}$ leads to protonation of acidic groups making the $\mathrm{C}$-terminus less negative, the $\mathrm{N}$-terminus more positive and reduce the overall net negative charge of the protein. This has at least three important consequences. First, this leads to significantly reduced electrostatic repulsion between $\alpha$-synuclein molecules favoring association, and therefore the protein aggregates faster. Second, the C-terminus of $\alpha$-synuclein might adopt a more compact structure at reduced $\mathrm{pH}$, which in combination with alterations of the long-range electrostatic interactions has been suggested to lead to faster aggregation [38, 39]. Third, low $\mathrm{pH}$ has been shown to transform $\alpha$-synuclein from its natively unfolded form to a partially folded conformation possibly resembling an intermediate aggregation species [40], which also may speed up the aggregation.

In this study, we show for the first time that $\alpha$-synuclein can fibrillate reproducibly without any agitation at $\mathrm{pH}$ 5.5-6.0. Other approaches previously used to increase reproducibility are mechanical stirring or vigorous shaking, without or with the addition of beads, stirrers or additives such as SDS [11, 41, 42], neither of which represent particularly physiological conditions. The physiological $\mathrm{pH}$ in cells is normally around 7.4; however, also lower $\mathrm{pH}$ may be biologically relevant as it occurs in specific cellular compartments. The $\mathrm{pH}$ is low in e.g. lysosomes and $\alpha$-synuclein present in microsomal vesicles has been shown to be more aggregation prone compared to cytosolic $\alpha$-synuclein [43]. Interestingly, the $\mathrm{pH}$ may decrease as much as 1.4 units [44] during oxidative and metabolic stresses, e.g. due to mitochondrial dysfunction, which has been implicated in PD. In agreement with this, oxidative stress has repeatedly been shown to promote $\alpha$-synuclein aggregation $[45,46]$.

\section{Association of monomeric $\alpha$-synuclein with artificial membranes}

Taking advantage of our reproducible kinetics we characterized the membrane association for monomeric, fibrillar and on-pathway (oligomeric) $\alpha$-synuclein. We used GUVs composed of DOPC, with or without DOPS or CL mixed in, as model membranes in buffered systems. As we observed no association between $\alpha$-synuclein and GUVs when using pure PC or at $\mathrm{pH} 7.5$ for any condition, membrane charge appears to be very important. At neutral $\mathrm{pH}, \alpha$-synuclein is negatively charged leading to repulsion of the anionic lipids PS and CL, whereas at $\mathrm{pH} 5.5$ the protein net charge will be closer to zero reducing the electrostatic repulsion. In agreement with previous work [47], interactions involving hydrophobic parts of the protein and lipids are not sufficient for association.

We never detected adsorption of monomeric $\alpha$-synuclein in any of the systems we studied. However, after a few hours of incubation together with GUVs containing either PS or CL, we observed that $\alpha$-synuclein associated with the membranes. As $\alpha$-synuclein eventually spontaneously aggregates even without agitation, most likely small aggregates formed during incubation, associating with the membranes. This would also explain why the labeled $\alpha$-synuclein appeared in patches on the GUVs, not covering the GUVs uniformly, when we used monomer as starting material. The non-uniform distribution in the membrane is also consistent with a continuous nucleated growth/aggregation of $\alpha$-synuclein on the anionic GUVs (Fig. 4), which is consistent with previous reports of membrane-bound $\alpha$-synuclein being able to seed the aggregation of cytosolic protein [48].

It is also possible that the lipids in the bilayer undergo partial segregation and form domains enriched in $\alpha$-synuclein together with anionic lipids (DOPS or CL) and relatively $\alpha$-synuclein-free domains enriched in zwitterionic DOPC. Complete lipid segregation, however, is unlikely as the domains cover areas clearly much larger than what would be expected on basis of the lipid composition. 
Association of “on-pathway” $\alpha$-synuclein oligomers with membranes

The adsorption by on-pathway species also occurred in segregated domains. Oligomeric $\alpha$-synuclein is reported to have higher affinity for lipids compared to monomers and fibrils $[49,50]$. We studied on-pathway $\alpha$-synuclein samples obtained after approximately $89 \%$ of the lag time for fibrillation. Such samples contain a mixture of aggregates of various sizes, but also some monomer and some yet not measurable amount of fibrils. Samples taken at equilibrium contain fibrillar as well as lower molecular species, although at such late time points fibrillar aggregates dominate over monomer and smaller oligomers [51]. In contrast to the "on-pathway" oligomeric species used here, other types of oligomeric $\alpha$-synuclein - "off-pathway" are also described in the literature $[12,52]$. These oligomers are typically trapped by additives and cannot form mature fibrils and therefore not used in the current study. In our system, the intermediate samples are truly on-pathway $\alpha$-synuclein species as the aggregation process will continue towards mature fibrils.

\section{Effects of the model lipid membrane composition}

When comparing different model membrane systems, we observed that $\alpha$-synuclein has a higher affinity for membranes containing CL compared to membranes containing PS, as no association is visible for $10 \mathrm{~mol} \%$ PS albeit adsorption is observed at an even lower overall charge for CL ( $3 \mathrm{~mol} \%$ ). Previous studies have demonstrated that $\alpha$-synuclein preferentially associates with membranes that contain anionic lipids, although at $\mathrm{pH} 7.4[47,53]$. Limited $\alpha$-synucleinmembrane association has also been shown with GUVs made with anionic lipids mixed with POPC and "offpathway" $\alpha$-synuclein oligomers at $\mathrm{pH} 7.4$ [54]. By contrast, another report suggests that $\alpha$-synuclein can interact with vesicles composed entirely of the zwitterionic lipid POPC [53].

In contrast to the monovalent lipid PS, CL is a divalent anionic lipid and thus has twice the charge and also twice the number of acyl chains, giving CL unique molecular properties. Although the concentration of CL in mitochondrial membranes is less than $10 \mathrm{~mol} \%$ it plays an important role in stabilizing and activating mitochondrial enzymes [55, 56]. $\alpha$-Synuclein can be found in mitochondria [57] and this association is affected by e.g. species and $\mathrm{pH}$. Toxic $\alpha$-synuclein-mitochondria interactions have recently been highlighted. $\alpha$-Synuclein co-localized with mitochondria in substantia nigra neurons and was able to induce fragmentation of mitochondria in vivo in addition to fragment artificial membranes consisting of $\mathrm{CL}$ and $\mathrm{PC}$ in vitro [18]. Here we show that $\alpha$-synuclein aggregates can continue to grow (Fig. 4) leading us to speculate that $\alpha$-synuclein binding to membranes could act as a nucleation site and possibly give rise to increased fraction of toxic species.

Interestingly, we see co-localization of protein and lipid in the GUV membrane (Figs. 2-3). The studies of the aggregation growth in the presence of anionic model membranes (Fig. 4) further imply that membrane lipids are incorporated into the growing $\alpha$-synuclein aggregates during prolonged incubation. Similar observations have been made with both IAPP, where the amyloid protein has been shown to extract lipid from membranes during the aggregation process [58], as well as $\alpha$-synuclein, which has been found to be able bind lipids [47]. More importantly, lipids have been found inclosed in the neuropathological Lewy bodies in brain neurons [1]. Membrane lipids have also been found tightly associated with amyloid plaques extracted from patients with other amyloid diseases [59].

\section{No transport of $\alpha$-synuclein over artificial membranes}

Emerging evidence from biological studies indicates that $\alpha$-synuclein is capable of spreading from cell to cell and seed aggregation [25-27, 60]. Recent findings suggest that bilayer defects caused by $\alpha$-synuclein oligomers or membrane instability are the basis for induced leakage [52,61]. Other models propose that amyloid formation changes the fluidity of the membrane or that the membrane is disrupted in the amyloid formation process $[58,62]$. In our study we clearly observed $\alpha$-synuclein associating with the charged model lipid membranes leading to membrane thickening, but had no indication of $\alpha$-synuclein, in any form, passing over the membrane. We never found monomeric $\alpha$-synuclein or the dye carboxyfluorescein (data not shown) inside the GUVs. Thus $\alpha$-synuclein does not enter the GUVs by spontaneous passage over the artificial membranes, which is in agreement with most other reports [54, 63, 64], although $\alpha$-synuclein has also been suggested to passively diffuse over the plasma membrane [63]. In cells, uptake of $\alpha$-synuclein has been suggested to occur through endocytosis [25, $43,60,65]$, which is a process we cannot model in our system. 


\section{Concluding remarks}

In conclusion, we show that $\alpha$-synuclein aggregates reproducibly at slightly acidic $\mathrm{pH}$ even without shaking. Using the highly reproducible aggregation we collected on-pathway oligomers and $\alpha$-synuclein fibrils and show that they associate with negatively charged model membranes. Furthermore, when investigating seeded $\alpha$-synuclein aggregation in presence of GUVs we find lipid and $\alpha$-synuclein co-localized in the GUV membrane. However, no transport of $\alpha$-synuclein was seen, indicating that the ability of $\alpha$-synuclein to enter cells is more complex than diffusive transport over cell membranes.

\section{ACKNOWLEDGMENTS}

This work was supported by the Swedish Research Council and its Linneaus programme OMM (S.L., E.S.), The Swedish Foundation for Strategic Research (E.S.), the Crafoord foundation (S.L), the Swedish Brain Foundation (P.B.), Söderberg Foundation (P.B.), Swedish Research Council (S.L, P.B), Human Frontier Science Program (P.B.), a European Research Council Advanced Award (PRISTINE-PD) (P.B.) and a private donation from Mr. Sven Astell (P.B). The authors wish to thank Erik Hellstrand for fruitful discussions.

\section{REFERENCES}

[1] Halliday GM, Ophof A, Broe M, Jensen PH, Kettle E, Fedorow H, Cartwright MI, Griffiths FM, Shepherd CE, \& Double KL (2005) Alpha-synuclein redistributes to neuromelanin lipid in the substantia nigra early in Parkinson's disease. Brain, 128, 2654-2664.

[2] Halliday GM, Holton JL, Revesz T, \& Dickson DW (2011) Neuropathology underlying clinical variability in patients with synucleinopathies. Acta Neuropathol (Berl), 122, 187204.

[3] Polymeropoulos MH, Lavedan C, Leroy E, Ide SE, Dehejia A, Dutra A, Pike B, Root H, Rubenstein. J, Boyer R, Stenroos ES, Chandrasekharappa S, Athanassiadou A, Papapetropoulos T, Johnson WG, Lazzarini AM, Duvoisin RC, Di Iorio G, Golbe LI, \& Nussbaum RL (1997) Mutation in the alpha-synuclein gene identified in families with Parkinson's disease. Science, 276, 2045-2047.

[4] Kruger R, Kuhn W, Muller T, Woitalla D, Graeber M, Kosel S, Przuntek H, Epplen JT, Schols L, \& Riess O (1998) Ala30pro mutation in the gene encoding alpha-synuclein in Parkinson's disease. Nat Genet, 18, 106-108.

[5] Zarranz JJ, Alegre J, Gomez-Esteban JC, Lezcano E, Ros R, Ampuero I, Vidal L, Hoenicka J, Rodriguez O, Atares B, Llorens V, Gomez Tortosa E, del Ser T, Munoz DG, \& de Yebenes JG (2004) The new mutation, e46k, of alphasynuclein causes Parkinson and lewy body dementia. Ann Neurol, 55, 164-173.
[6] Chartier-Harlin MC, Kachergus. J, Roumier C, Mouroux V, Douay X, Lincoln S, Levecque C, Larvor L, Andrieux J, Hulihan M, Waucquier N, Defebvre L, Amouyel P, Farrer M, \& Destee A (2004) Alpha-synuclein locus duplication as a cause of familial Parkinson's disease. Lancet, 364, 1167-1169.

[7] Singleton AB, Farrer M, Johnson. J, Singleton A, Hague S, Kachergus J, Hulihan M, Peuralinna T, Dutra A, Nussbaum R, Lincoln S, Crawley A, Hanson M, Maraganore D, Adler C, Cookson MR, Muenter M, Baptista M, Miller D, Blancato J, Hardy J, \& Gwinn-Hardy K (2003) Alpha-synuclein locus triplication causes Parkinson's disease. Science, 302, 841 .

[8] Bartels T, Choi JG, \& Selkoe DJ (2011) Alpha-synuclein occurs physiologically as a helically folded tetramer that resists aggregation. Nature, 477, 107-110.

[9] Winner B, Jappelli R, Maji SK, Desplats PA, Boyer L, Aigner S, Hetzer C, Loher T, Vilar M, Campioni S, Tzitzilonis C, Soragni A, Jessberger S, Mira H, Consiglio A, Pham E, Masliah E, Gage FH, \& Riek R (2011) In vivo demonstration that alphasynuclein oligomers are toxic. Proc Natl Acad Sci U S A, 108, 4194-4199.

[10] Wakabayashi K, Tanji K, Mori F, \& Takahashi H (2007) The lewy body in Parkinson's disease: Molecules implicated in the formation and degradation of alpha-synuclein aggregates. Neuropathology, 27, 494-506.

[11] Danzer KM, Haasen D, Karow AR, Moussaud S, Habeck M, Giese A, Kretzschmar H, Hengerer B, \& Kostka M (2007) Different species of alpha-synuclein oligomers induce calcium influx and seeding. J Neurosci, 27, 9220-9232.

[12] Giehm L, Svergun DI, Otzen DE, \& Vestergaard B (2011) Low-resolution structure of a vesicle disrupting $\alpha$-synuclein oligomer that accumulates during fibrillation. Proc Natl Acad Sci U S A, 108, 3246-3251.

[13] Lashuel HA, Petre BM, Wall J, Simon M, Nowak RJ, Walz T, \& Lansbury Jr PT (2002) [alpha]-synuclein, especially the Parkinson's disease-associated mutants, forms pore-like annular and tubular protofibrils. J Mol Biol, 322, 1089-1102.

[14] Nakamura K, Nemani VM, Wallender EK, Kaehlcke K, Ott M, \& Edwards RH (2008) Optical reporters for the conformation of alpha-synuclein reveal a specific interaction with mitochondria. J Neurosci, 28, 12305-12317.

[15] Devi L, Raghavendran V, Prabhu BM, Avadhani NG, \& Anandatheerthavarada HK (2008) Mitochondrial import and accumulation of alpha-synuclein impair complex i in human dopaminergic neuronal cultures and Parkinson disease brain. J Biol Chem, 283, 9089-9100.

[16] Middleton ER, \& Rhoades E (2010) Effects of curvature and composition on alpha-synuclein binding to lipid vesicles. Biophys, J 99, 2279-2288.

[17] Stockl M, Fischer P, Wanker E, \& Herrmann A (2008) Alpha-synuclein selectively binds to anionic phospholipids embedded in liquid-disordered domains. J Mol Biol, 375, 1394-1404.

[18] Nakamura K, Nemani VM, Azarbal F, Skibinski G, Levy JM, Egami K, Munishkina L, Zhang J, Gardner B, Wakabayashi J, Sesaki H, Cheng Y, Finkbeiner S, Nussbaum RL, Masliah E, \& Edwards RH (2011) Direct membrane association drives mitochondrial fission by the Parkinson disease-associated protein alpha-synuclein. J Biol Chem, 286, 20710-20726.

[19] Quinn PJ, Kagan VE (2002) eds, Subcellular Biochemistry: Phospholipid metabolism in apoptosis, vol. 36, Kluwer Academic/Plenum Publishers, London.

[20] Li JY, Englund E, Holton JL, Soulet D, Hagell P, Lees AJ, Lashley T, Quinn NP, Rehncrona S, Bjorklund A, Widner H, Revesz T, Lindvall O, \& Brundin P (2008) Lewy bodies in 
grafted neurons in subjects with Parkinson's disease suggest host-to-graft disease propagation. Nat Med, 14, 501-503.

[21] Kordower JH, Chu Y, Hauser RA, Freeman TB, \& Olanow CW (2008) Lewy body-like pathology in long-term embryonic nigral transplants in Parkinson's disease. Nat Med, 14, 504-506.

[22] Brundin P, Li JY, Holton JL, Lindvall O, \& Revesz T (2008) Research in motion: The enigma of Parkinson's disease pathology spread. Nat Rev Neurosci, 9, 741-745.

[23] Angot E, Steiner JA, Hansen C, Li JY, \& Brundin P (2010) Are synucleinopathies prion-like disorders? Lancet Neurol, $\mathbf{9}$, 1128-1138.

[24] Lee SJ, Desplats P, Sigurdson C, Tsigelny I, \& Masliah E (2010) Cell-to-cell transmission of non-prion protein aggregates. Nature reviews. Neurology, 6, 702-706.

[25] Hansen C, Angot E, Bergstrom AL, Steiner JA, Pieri L, Paul G, Outeiro TF, Melki R, Kallunki P, Fog K, Li JY, \& Brundin P (2011) Alpha-synuclein propagates from mouse brain to grafted dopaminergic neurons and seeds aggregation in cultured human cells. J Clin Invest, 121, 715-725.

[26] Kordower JH, Dodiya HB, Kordower AM, Terpstra B, Paumier K, Madhavan L, Sortwell C, Steece-Collier K, \& Collier TJ (2011) Transfer of host-derived alpha synuclein to grafted dopaminergic neurons in rat. Neurobiol Dis, 43, 552-557.

[27] Desplats P, Lee HJ, Bae EJ, Patrick C, Rockenstein E, Crews L, Spencer B, Masliah E, \& Lee SJ (2009) Inclusion formation and neuronal cell death through neuron-to-neuron transmission of alpha-synuclein. Proc Natl Acad Sci U S A, 106, 13010-13015.

[28] Angelova MI, \& Dimitrov DS (1986) Liposome electroformation. Faraday Discuss, 81, 303-311.

[29] Dimitrov DS, \& Angelova MI (1988) Lipid swelling and liposome formation mediated by electric-fields. Bioelectrochem Bioenerg, 19, 323-336.

[30] Ambroggio EE, \& Bagatolli LA (2009) Membrane-active peptides: Methods and results on structure and function. In: Castanho M, editor. Giant unilamellar vesicles, fluorescence microscopy and lipid-peptide interactions. La Jolla, International University Line, CA, pp. 179-200.

[31] Linse S, Hellstrand E, Boland B, \& Walsh DM (2010) Amyloid beta-protein aggregation produces highly reproducible kinetic data and occurs by a two-phase process. Acs Chemical Neuroscience 1, 13-18.

[32] Biancalana M, Makabe K, Koide A, \& Koide S (2009) Molecular mechanism of thioflavin-t binding to the surface of beta-rich peptide self-assemblies. J Mol Biol, 385, 1052-1063.

[33] Hellstrand E, Sparr E, \& Linse S (2010) Retardation of abeta fibril formation by phospholipid vesicles depends on membrane phase behavior. Biophys J, 98, 2206-2214.

[34] Hoyer W, Cherny D, Subramaniam V, \& Jovin TM (2004) Impact of the acidic c-terminal region comprising amino acids 109-140 on alpha-synuclein aggregation in vitro. Biochemistry (Mosc), 43, 16233-16242.

[35] Karpinar DP, Balija MB, Kugler S, Opazo F, Rezaei-Ghaleh N, Wender N, Kim HY, Taschenberger G, Falkenburger BH, Heise H, Kumar A, Riedel D, Fichtner L, Voigt A, Braus GH, Giller K, Becker S, Herzig A, Baldus M, Jackle H, Eimer S, Schulz JB, Griesinger C, \& Zweckstetter M (2009) Prefibrillar alpha-synuclein variants with impaired beta-structure increase neurotoxicity in Parkinson's disease models. EMBO $J, 28,3256-3268$.

[36] Giannakis E, Pacifico. J, Smith DP, Hung LW, Masters CL, Cappai R, Wade JD, \& Barnham KJ (2008) Dimeric structures of alpha-synuclein bind preferentially to lipid membranes. Biochim Biophys Acta, 1778, 1112-1119.
[37] Outeiro TF, Putcha P, Tetzlaff JE, Spoelgen R, Koker M, Carvalho F, Hyman BT, \& McLean PJ (2008) Formation of toxic oligomeric alpha-synuclein species in living cells. PLOS ONE, 3, e1867.

[38] Cho M-K, Nodet G, Kim H-Y, Jensen MR, Bernado P, Fernandez CO, Becker S, Blackledge M, \& Zweckstetter M (2009) Structural characterization of alpha-synuclein in an aggregation prone state. Protein Sci, 18, 1840-1846.

[39] Wu K-P, Weinstock DS, Narayanan C, Levy RM, \& Baum J (2009) Structural reorganization of [alpha]-synuclein at low ph observed by nmr and remd simulations. J Mol Biol, 391, 784-796.

[40] Uversky VN, Li J, \& Fink AL (2001) Evidence for a partially folded intermediate in alpha-synuclein fibril formation. J Biol Chem, 276, 10737-10744.

[41] Giehm L, \& Otzen DE (2010) Strategies to increase the reproducibility of protein fibrillization in plate reader assays. Anal Biochem, 400, 270-281.

[42] Kim H-Y, Cho M-K, Kumar A, Maier E, Siebenhaar C, Becker S, Fernandez CO, Lashuel HA, Benz R, Lange A, \& Zweckstetter M (2009) Structural properties of pore-forming oligomers of $\alpha$-synuclein. J Am Chem Soc, 131, 1748217489.

[43] Lee H-J, Patel S, \& Lee S-J (2005) Intravesicular localization and exocytosis of $\{$ alpha $\}$-synuclein and its aggregates. J Neurosci, 25, 6016-6024.

[44] Cole NB, DiEuliis D, Leo P, Mitchell DC, \& Nussbaum RL (2008) Mitochondrial translocation of [alpha]-synuclein is promoted by intracellular acidification. Exp Cell Res, 314, 2076-2089.

[45] Takahashi M, Ko LW, Kulathingal J, Jiang P, Sevlever D, \& Yen SH (2007) Oxidative stress-induced phosphorylation, degradation and aggregation of alpha-synuclein are linked to upregulated ck2 and cathepsin d. Eur J Neurosci, 26, $863-$ 874.

[46] Li W, Jiang H, Song N, \& Xie J (2011) Oxidative stress partially contributes to iron-induced alpha-synuclein aggregation in sk-n-sh cells. Neurotox Res, 19, 435-442.

[47] Ramakrishnan M, Jensen PH, \& Marsh D (2003) Alphasynuclein association with phosphatidylglycerol probed by lipid spin labels. Biochemistry (Mosc), 42, 12919-12926.

[48] Lee HJ, Choi C, \& Lee SJ (2002) Membrane-bound alphasynuclein has a high aggregation propensity and the ability to seed the aggregation of the cytosolic form. J Biol Chem, 277, 671-678.

[49] Volles MJ, Lee SJ, Rochet JC, Shtilerman MD, Ding TT, Kessler JC, \& Lansbury PT Jr (2001) Vesicle permeabilization by protofibrillar alpha-synuclein: Implications for the pathogenesis and treatment of Parkinson's disease. Biochemistry (Mosc), 40, 7812-7819.

[50] Smith DP, Tew DJ, Hill AF, Bottomley SP, Masters CL, Barnham KJ, \& Cappai R (2008) Formation of a high affinity lipid-binding intermediate during the early aggregation phase of a-synuclein. Biochemistry (Mosc), 47, 1425-1434.

[51] Hellstrand E, Boland B, Walsh DM, \& Linse S (2010) Amyloid beta-protein aggregation produces highly reproducible kinetic data and occurs by a two-phase process. Acs Chemical Neuroscience, 1, 13-18.

[52] van Rooijen BD, Claessens MM, \& Subramaniam V (2010) Membrane permeabilization by oligomeric alpha-synuclein: In search of the mechanism. PLOS ONE, 5, e14292.

[53] Rhoades E, Ramlall TF, Webb WW, \& Eliezer D (2006) Quantification of alpha-synuclein binding to lipid vesicles using fluorescence correlation spectroscopy. Biophys $J, 90$, 4692-4700. 
[54] van Rooijen BD, Claessens MM, \& Subramaniam V (2008) Membrane binding of oligomeric alpha-synuclein depends on bilayer charge and packing. FEBS Lett, 582, 3788-3792.

[55] Lewis R, \& McElhaney R (2009) The physicochemical properties of cardiolipin bilayers and cardiolipin-containing lipid membranes. Biochimica et Biophysica Acta (BBA) - Biomembranes, 1788, 2069-2079.

[56] Pope S, Land JM, \& Heales SJR (2008) Oxidative stress and mitochondrial dysfunction in neurodegeneration cardiolipin a critical target? Biochimica Et Biophysica ActaBioenergetics, 1777, 794-799.

[57] Devi L, \& Anandatheerthavarada HK (2010) Mitochondrial trafficking of app and alpha synuclein: Relevance to mitochondrial dysfunction in Alzheimer's and Parkinson's diseases. Biochim Biophys Acta, 1802, 11-19.

[58] Sparr E, Engel MF, Sakharov DV, Sprong M, Jacobs J, de Kruijff B, Hoppener JW, \& Killian JA (2004) Islet amyloid polypeptide-induced membrane leakage involves uptake of lipids by forming amyloid fibers. FEBS Lett, 577, 117-120.

[59] Gellermann GP, Appel TR, Tannert A, Radestock A, Hortschansky P, Schroeckh V, Leisner C, Lutkepohl T, Shtrasburg S, Rocken C, Pras M, Linke RP, Diekmann S, \& Fandrich M (2005) Raft lipids as common components of human extracellular amyloid fibrils. Proc Natl Acad Sci U A, 102, 6297-6302.
[60] Volpicelli-Daley LA, Luk KC, Patel TP, Tanik SA, Riddle DM, Stieber A, Meaney DF, Trojanowski JQ, \& Lee VM (2011) Exogenous alpha-synuclein fibrils induce lewy body pathology leading to synaptic dysfunction and neuron death. Neuron, 72, 57-71.

[61] Stockl M, Claessens MM, \& Subramaniam V (2012) Kinetic measurements give new insights into lipid membrane permeabilization by alpha-synuclein oligomers. Mol Biosyst, $\mathbf{8}$, 338-345.

[62] Yang AJ, Chandswangbhuvana D, Margol L, \& Glabe CG (1998) Loss of endosomal/lysosomal membrane impermeability is an early event in amyloid abeta1-42 pathogenesis. $J$ Neurosci Res, 52, 691-698.

[63] Lee H-J, Suk J-E, Bae E-J, Lee J-H, Paik SR, \& Lee SJ (2008) Assembly-dependent endocytosis and clearance of extracellular [alpha]-synuclein. Int J Biochem Cell Biol, 40, 1835-1849.

[64] Pandey AP, Haque F, Rochet JC, \& Hovis JS (2009) Clustering of alpha-synuclein on supported lipid bilayers: Role of anionic lipid, protein, and divalent ion concentration. Biophys J, 96, 540-551.

[65] Jang A, Lee HJ, Suk JE, Jung JW, Kim KP, \& Lee SJ (2010) Non-classical exocytosis of alpha-synuclein is sensitive to folding states and promoted under stress conditions. $\mathrm{J} \mathrm{Neu}$ rochem, 113, 1263-1274. 